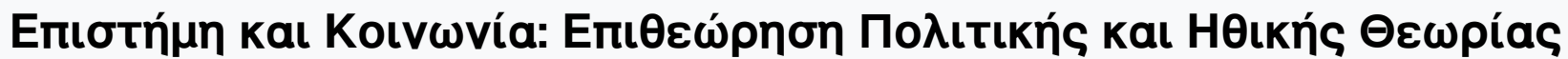

Tó 19 (2008)

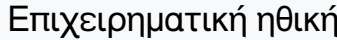

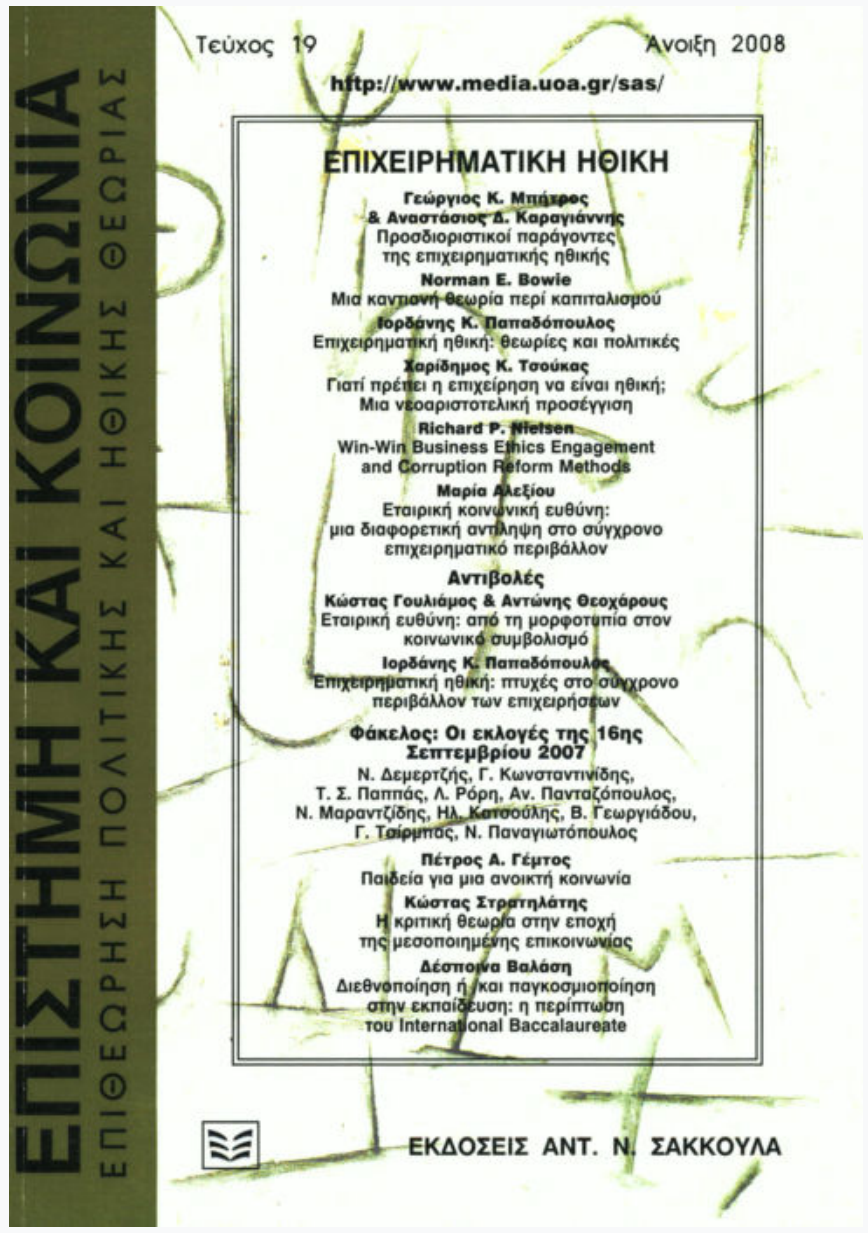

\section{Win-Win business ethics engagement and corruption reform methods}

Richard P. Nielsen

doi: $10.12681 /$ sas.658

Copyright (c) 2015, Richard P. Nielsen

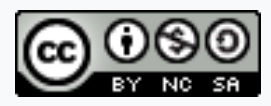

Aঠ¿ıа Xpńбnৎ Creative Commons Attribution-NonCommercial-ShareAlike 4.0.

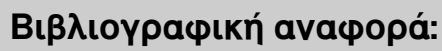

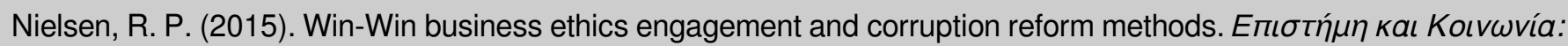

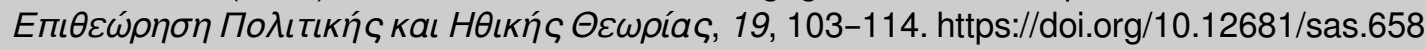




\section{Win-Win Business Ethics Engagement and Corruption Reform Methods}

Richard P. Nielsen

There has been comparatively less work done on how to effectively engage with and reform unethical and corrupt behaviors in business world; behaviors that can be both legal and illegal. According to the author, however, the research that has been done is very encouraging. Effective business ethics methods can be very profitable and sustainable. Effective business ethics methods can be learned and taught. Further, effective business ethics methods can help cause and stimulate better and greater socioeconomic development.

In his paper, he first considers nine types of effective business ethics engagement and corruption reform methods. Second, he examines in some detail six win-win methods with real case examples. Third, theoretical foundations for win-win methods and why win-win ethical business practices and relationships are profitable and sustainable are considered. Fourth, he discusses strengths and limitations of win-win methods. For the author, winwin method can help facilitate ethical and mutually prosperous association.

There has been a great deal of research that documents the inverse relationship between socioeconomic development and the amount of corruption and unethical business behavior. That is, wealthier countries for the most part have less corruption and unethical business behavior than poor countries. However, when high levels of economic development become entangled with predatory political ambitions, there can be just as much if not more

• Professor, Boston College and ALBA, richard.nielsen@bc.edu. The author would very much like to thank Dimitris Daskalopoulos, Dionisis Nikolaou, and the Aristides Daskalopoulos Foundation for supporting ALBA and its work in business ethics and for the development of this article. He also thanks Mr. Ebeoglou for his very helpful insights and constructive criticisms of this paper. Furthermore, he would like to thank one of the founders of ALBA, Stelios Argyros, for his practical idealism and for helping him learn about the practical realities and challenges in helping build more ethical and prosperous organizations and communities. 
unethical business behavior and corruption than in poorer countries. Nonetheless, corruption is a key obstacle to socioeconomic development. Conversely, long term, sustainable win-win ethical business behaviors and low levels of corruption facilitate socioeconomic development.

Why is this the case? This question will be addressed in more detail later in this paper, but generally, long term win-win ethical business relationships and behaviors are more profitable and sustainable than unethical business behaviors. Also, in many poor countries where such profitable, long term, and sustainable relationships and economic institutions are relatively scarce, corruption can appear to be an easier and more sure path to short-term higher income and wealth.

That is not to say there are no corruption and/or business ethics problems in developed economies. Unethical and corrupt behaviors may be analogous to disease; they can be reduced and controlled, but given our flawed human natures and corresponding human organizational systems, it is probably unrealistic to think that corrupt and unethical behaviors can be eliminated completely.

Also and as I mentioned before, sometimes unethical business behaviors become entangled with insatiable desires for power, political power, and even power for its own sake in both developed and less developed countries. Further, there are some countries such as the Scandinavian countries that rank very low with respect to internal corruption, but when they operate in the corrupt sectors of poorer countries, they rank high for example as payers of extortion demands by government officials.

On a more micro level, there has also been a great deal of research done on understanding what the key business ethics issues are in both developed and emerging market economies such as: health, safety, and environmental problems; government officials extorting money from managers, managers bribing government officials; managers extorting money from vendors, vendors bribing managers; fraud and abuse of investors; sexual harassment and abuse of employees; class, gender, racial, and ethnic discrimination, etc.

There has also been quite a bit of work done on relationships between ethics and legal issues. For example, Ricoeur (1984) developed a dynamic feedback, process model where experience can inform ethics, ethics can stimulate political activity, political activity can result in legal changes, and 
experience with laws can inform ethical judgments about changing laws, and so on. At any moment in this continuing process, there can be unethical and legal behaviors, ethical and illegal behaviors, unethical and illegal behaviors, and legal and ethical behaviors.

Unfortunately, there has been comparatively less work done on how to effectively engage with and reform unethical and corrupt behaviors that can be both legal and illegal. Nonetheless, the research that has been done is very encouraging. Effective business ethics methods can be very profitable and sustainable. Effective business ethics methods can be learned and taught. Further, effective business ethics methods can help cause and stimulate better and greater socioeconomic development.

This paper first considers nine types of effective business ethics engagement and corruption reform methods. Second, we will focus on win-win methods with real case examples. Third, theoretical foundations for win-win methods and why win-win ethical business practices and relationships are profitable and sustainable are considered. Fourth, we'll discuss strengths and limitations of win-win methods.

\section{Varieties of Ethics Engagement and Corruption Reform Methods}

There are at least nine sets of business ethics engagement and corruption reform methods.

1. Ethics win-lose methods such as prosecutions, compliance codes, and secret whistle blowing;

2. Ethics win-win reward and negotiating methods;

3. Ethics reasoning criteria and arguments;

4. Dialogic presentation, discussion, and decision making methods;

5. Ethics internal due process systems;

6. Comprehensive organizational ethics program development and turnaround methods;

7. Ethical investing screening and engagement methods;

8. Alternative institution building methods; and,

9. Social movement methods.

It is generally not practical to think in terms of a best set of ethics engagement and corruption reform methods. Depending upon the individual, or- 
ganizational, and environmental obstacles and causes of ethics and corruption problems, different types of methods are more and less appropriate. We're focusing here on win-win methods. The key reasons for this focus on win-win methods are that win-win methods can be more effective, profitable, and sustainable than, for example, the sometimes more idealistic and less effective dialogic methods while being less destructive than the often effective, at least in the short-run, win-lose methods. However and not withstanding the benefits of other types of methods such as dialogic and win-win methods, short-run win-lose methods are sometimes the only effective methods. So depending on the situation, different types of methods are more and less effective and appropriate.

We're considering six types of win-win methods here. There are others. The methods considered here are: (1) share costs-resources for a level playing field; (2) trade resources; (3) develop and expand the size of the solution rather than concentrate on division; (4) experiment; (5) contingency; and, (6) seniority, taking turns, random selection.

As the cases will illustrate, win-win methods are not perfect. In addition, there can be win-win solutions that are also unethical.

\section{Win-Win Methods}

\section{Method 1: Share costs and resources for a level playing field.}

If only one company among competitors adopts an ethical behavior, there can be competitive disadvantages for that company. If only one company adopts a higher cost standard, this company can be at a competitive disadvantage relative to its competitors who experience lower costs since they have not adopted such higher cost standards. To solve this problem, companies can work together to establish a level playing field and agree on higher quality and cost standards and/or work with other groups to pass legislation that requires such standards.

For example, some automobile and energy companies have worked together and with legislators to agree on and support engine emission standards. Similarly, pharmaceutical companies have worked with each other and legislators to establish common drug testing standards and advertising standards. Nonetheless, much more needs to be done in these health and safety areas. 
Sometimes, companies can also work together to resist government extortion. For example, in one Mediterranean country the three distributors of a high technology product produced by three different multinational companies from three different countries all agreed to stop paying extortion to tax inspectors and to pool resources for help from law firms and accounting firms. In the face of such united resistance, the tax inspectors stopped extorting money from the three companies in this industry. This is possible.

\section{Method 2: Trade resources.}

A Northern European pharmaceutical company made a win-win deal with a North African government official. The Health Minister in this country proposed that the company could sell their products to the Ministry at a high price in exchange for an extortion payment to the Minister, but if the company did not pay the extortion, it would not be permitted to do business in the country. In exchange for not having to make the extortion payment to the Minister of Health, the company agreed to locate a processing plant in a particularly disadvantaged economic location and sell its products at its normal prices to the Ministry. This deal was a win for the company because it was able to sell its products at their normal prices to the Ministry and in the country without paying the extortion. In addition, the disadvantaged economic location was a lower cost location than the location the company originally had in mind. It was a win for the country since the country received high quality medical products at normal prices as well as jobs in an area where jobs were very much needed. It was a win for the Minister and the Minister's political party in the sense that the Minister and his party received some good publicity for taking credit for locating the company and its jobs in an area where they were very much needed. Unfortunately, this helped the public image of a corrupt public official and his Party so it's also an example of how win-win solutions are often not perfect and can be flawed. However, the management of the company considered this win-win solution better than what it considered the unethical win-win solution of paying the extortion and in exchange receiving permission to enter the country and receive high prices for its medicines.

One of the reforms of the Sarbanes-Oxley Act was the agreement to reward financial analysts for the accuracy of their estimates rather than for 
their cooperation with investment bankers in selling investment banking services. Previous to this agreement, it was common practice for financial analysts to accompany investment bankers on sales calls to potential clients where clients were promised favorable analyst coverage and recommendations in exchange for investment banking advising services and financing services. That conflict of interest based win-win deal among investment bankers, analysts, and investment banking clients is now illegal as well as unethical.

\section{Method 3: Development - Introduce new players/resources to expand size more than divide.}

A real estate development company in a North American country wanted to buy a house and a piece of land from a nonprofit social service agency. The nonprofit organization served as a half-way house for recovering drug addicts in an area of, for the most part, single-family homes. The neighbors were not happy about having such an institution in their neighborhood. The amount of money that the nonprofit organization needed to move to a more suitable location was more than the property was worth as a single-family house. The real estate developer put together a deal such that the zoning was changed with the support of the neighbors to build an apartment building that enabled the property to be worth more so that the nonprofit organization could receive more money for the property. Value was created and expanded for all. The real estate company developed a larger and more profitable property, the nonprofit organization was able to move into larger and better facilities in a more suitable and different neighborhood, and the local community and neighbors won in the sense that the neighborhood returned to its former residential state.

Another example. A university teaching hospital was experiencing difficulty in receiving adequate research funds from government and nonprofit foundations. The university contacted a pharmaceutical company and developed an expanded win-win deal. The university received funding from the pharmaceutical company, the university and the company developed and tested better medicines and shared in the profits of the medicines, patients received better medicines, poorer and uninsured patients received subsidized medicines, research doctors received greater research funding, and taxpayers 
did not have to pay increased taxes to support the research needed for better health care.

\section{Method 4: Experiment.}

It was brought to the attention of the Managing Director of a manufacturing company in a Mediterranean country, that his company had a much worse safety record than the European average. The Managing Director was concerned. At first he thought that the problem might be old equipment or poorly trained plant managers. However, the managers were very well educated engineers and the equipment was not old. It was suggested that the company do an experiment. In three plants, the plant mangers were told that in the next performance appraisal and reward period, managers would be evaluated for safety numbers as well as cost numbers and part of the bonus would depend on the safety numbers. Safety improved in the following year and because of the positive results of the experiment, the modified performance appraisal and compensation system was adopted throughout the company. The safety record improved and even exceeded the European averages.

Board members of a very large sports equipment company from a developed country were discussing whether or not to engage with their suppliers from poor, emerging market countries about dangerous and unhealthy "sweatshop" working conditions in their factories. One board member suggested that they should not try to engage with their suppliers on the issue because it would raise costs and cause a competitive disadvantage. A second board member advocated that the company should engage because of the severe health and safety problems. A third board member suggested an experiment with one of their suppliers where they would try to both reduce costs and improve health and safety issues. The experiment worked and the company is now working with more suppliers to improve health and safety conditions that also reduce costs.

Within this same company, a similar Board discussion occurred concerning the long hours worked by the employees in the 'sweat shop' factories. An experiment is currently being conducted whereby the company is giving this factory more lead time on orders so that they can schedule work such that less overtime hours and costs are required. 
Another example. A social-ethical investing mutual fund engaged with one of the world's largest retailers about its packing policies which the social-ethical investing mutual fund considered harmful to the environment. The retailer agreed to experiment with new packaging designs that might be both more environmentally friendly and lower cost. Several of the experiments worked and the new packaging designs have been adopted by the retailing company.

\section{Method 5: Contingency.}

Sometimes, there can be disagreements about whether a behavior should be permitted because of different expectations of the consequences of the behavior. Instead of a win-lose power struggle over whether the behavior is permitted, contingency can be a win-win solution. For example, in one European country, there was a dispute about whether to permit the construction of processing plants in an environmentally sensitive area. Instead of a winner take all solution of either permitting the processing plants or not, the two opposing sides agreed that if the pollution exceeded a certain level, the plants would be closed.

Another example. A pharmaceutical company and a regulatory agency had a disagreement about whether it was safe to run a complete legally required test of a new chemotherapy drug for advanced cancer patients. Instead of saying either yes or not to the testing of the drug, the parties agree to a contingency testing scheme whereby the testing would be cancelled early if any of the cancer patients experienced the feared severe negative consequences. Tests were stopped for some of the drugs and continued for others.

\section{Method 6: Seniority, random selection, taking turns.}

Sometimes, it can be difficult to make meaningful and fair choices among alternative resource allocations. The methods of seniority, taking turns, and random selection are sometimes considered as ethical and win-win solutions to such problems. For example, in some employment areas, the work done by a group of employees is for the most part the same. Nonetheless, increased pay can be an important motivator but is hard to administer on the basis of merit since all the employees do essentially the same type of work. What is a 
fair way of allocating pay increases? In such situations, some organizations and unions agree to allocate scarce compensation resources according to seniority.

On a different yet parallel issue, a problem in the allocation of scarce organ transplants is how to ethically allocate the scarce organs among equally needy patients. In such cases where there are more candidates that the protocol criteria can assign the organs to, random selection is sometimes used.

Similarly, where there are scarce resources available to essentially equal candidates such as travel resources to conferences, technician help, use of computing facilities, secretarial help, etc., competing parties sometimes agree that a fair way to allocate the scarce resources is taking turns. This type of solution is often considered more ethical than for example allocating the scarce resources according to political favoritism.

\section{Theoretical foundations for win-win methods}

Theoretical support for win-win method comes from at least four different fields: game theory, strategic management, transaction cost economics, and philosophy.

With respect to game theory, Robert Axelrod (1984) in his MacArthur prize winning book The Evolution of Cooperation invited scientists from around the world to participate in a computer simulation tournament to test competing game theory strategies. He found that consistent, win-win, cooperative interactions among win-win players was the most successful strategy compared with various types of defection and competitive strategies. That is and with respect to socioeconomic development, long-term, cooperative, win-win business behaviors produce better and more sustainable socioeconomic development than the short-run oriented win-lose and defection strategies. Axelrod also found that such win-win, sustainable strategies can be taught and learned and practiced effectively.

There is also some support for cooperative win-win strategies within strategic management. For example, from my own work (Nielsen, 1988) I found that organizations that adopt cooperative strategies can add value, increase market share, and increase profitability from cooperative strategies as 
well as competitive strategies. Recently, Huxham and Vangen (2005) have considered both the theory and practice of cooperative strategy.

There is also a great deal of support for win-win approaches within economic theory. For example, in the area of transaction cost economics, Williamson and Masden (1999), in their book, The Economics of Transaction Costs, found that transaction costs are lower and profits higher when we do many win-win transitions with the same players rather than many different win-lose transactions with many different players.

Within philosophy, there is also normative support for win-win approaches. For example, Habermas in his 1984 book, The Theory of Communicative Action, found that in a world of conflicting and different traditions, dialogic approaches to ethics that search for win-win solutions can be more practical, peaceful, and sustainable than more competitive or adversarial approaches. Similarly, within contract ethics, Gauthier (1986) in his book, Morals By Agreement, found that voluntary, ethical agreements can be better and more sustainable than imposed solutions. It is also recognized in philosophy that win-win solutions can be both ethical and unethical.

\section{Strengths and limitations of win-win methods}

As the cases considered above indicate, win-win ethics methods can be effective and they can be taught and learned. As the strategy, game theory, and transaction cost literatures suggest, win-win methods can also be more profitable and sustainable and conducive to long-term socioeconomic development than win-lose behaviors. A mixed advantage and disadvantage of win-win ethics method is that it can be effective without belief conversion. This makes it easier to make the agreement, but perhaps harder to sustain the agreement in difficult times. As Habermas (1984) has pointed out, communicative, win-win ethics methods can be effective in cross-cultural situations where there is relatively little overlap between cultures. While many ethics philosophers prefer deductive reasoning, win-win ethics method can be more effective with those of us, and I include myself in this group, who learn more from experience than deductive reasoning.

There are limitations to all methods including win-win methods. A key limitation is that win-win solutions may not be materially, physically possible, at least in the short-run. That is, there may be no win-win ethical 
solution available in the short-run. In addition and unfortunately, sometimes people with more power sometimes prefer to impose their power based positions on others, rather than engage in dialog or win-win deal making. As referred to before, sometimes the power for the sake of power is more important than the money and this can be true in both developed and poorer countries. There are some countermeasures to such behaviors, but there are sometimes no effective counter measures available to the imposition of power based unethical behaviors. Also and as referred to above, win-win processes may foster little ethical learning or belief conversion toward the ethical which may have sustainability problems when short-term conditions are more difficult and less favorable to win-win ethical outcomes. In addition, with hot, emotional issues such as ethics, it can be difficult to remain analytical and win-win. As some of the above cases indicate, some solutions can be win-win and unethical or at least flawed with respect to ethics. Further, some people with a more purist inclination believe it is unethical to make win-win deals when ethics is involved. Finally, in the extreme vendetta like and/or revenge situations, both more and less powerful people may prefer win-lose and even lose-lose behaviors which is another argument in favor of win-win instead of win-lose behaviors in the first place.

\section{Conclusion}

As referred to above in the introduction section, there are at least nine sets of ethics methods. Win-win methods are only one set, but a very important set. They can be effective and profitable. They can stimulate and cause long-term, sustainable profitability, relationships, and socio-economic development. Much depends on what Aristotle referred to as phronesis, practical wisdom or sagacity. Depending on the individuals, organizations, and political-economic environments involved, different methods are more and less appropriate. The methods can be learned, taught, and practiced effectively. The more they are learned, taught, and practiced, the more they can help to stimulate and cause long-term, sustainable, socioeconomic development. If we care about ethics; if we care about trying to help make our realities more ethical, prosperous, and sustainable; if we study and try to understand which methods are more and less appropriate and practical; and, if we have some of that wonderful Greek idea and behavior of not just philo- 
sophia (love of understanding) but also philo-timo (love of honorable action), together, we can help build and sustain more ethical and prosperous organizations and realities. As Aristotle urged us, 'The student of ethics must apply himself to politics' and as the Irish political philosopher Edmund Burke observed, 'When bad men combine, the good must associate; else they will fall one by one, an unpitied sacrifice in a contemptible struggle.' Winwin method can help facilitate ethical and mutually prosperous association.

\section{References}

Axelrod, R. (1984). The Evolution of Cooperation, New York: Basic Books.

Gauthier, D. (1986). Morals By Agreement. Oxford: Clarendon Press.

Huxham, Ch. \& Siv Vangen (2005). Managing to Collaborate: The Theory and Practice of Collaborative Advantage. London: Routledge.

Nielsen, R. P. (1988). 'Cooperative Strategy', Strategic Management Journal, 9, 5: 475-492.

Nielsen, R. P. (1996). The Politics of Ethics, Oxford University Press.

Ricoeur, P. (1984). Time and Narrative. Chicago: University of Chicago Press.

Williamson, Ol. E. \& S. E. Masden (1999). The Economics of Transaction Costs. Elgar Books. 